\title{
The Effect of Fracture of Ulnar Styloid on Rotational Movements of the Forearm after Extraarticular Fractures of Distal Radius
}

\author{
Ali Karbalaeikhani ${ }^{1}$, Alireza Saied ${ }^{2}$, Amirreza Sadeghifar ${ }^{2 *}$ \\ ${ }^{1}$ Imam Reza (501) Hospital, AJA University of medical sciences, Tehran, Iran \\ ${ }^{2}$ Kerman Neuroscience research center, Kerman University of medical sciences, Kerman, Iran \\ E-mail: amirsf2000@yahoo.com \\ Received February 3, 2011; revised April 25, 2011; accepted April 29, 2011
}

\begin{abstract}
Introduction: Since distal radius fractures are among the most common fractures encountered in orthopedics and one of their common complications is restriction of rotational movements of the wrist and forearm, identification of factors affecting this loss of motion is of importance. This study was conducted to evaluate the relation between extraarticular distal radius fractures associated with fracture of ulnar styloid and the rotational movements of the wrist and forearm. Patients and methods: 47 patients with an extraarticular distal radius fracture were enrolled in a prospective case control study. The patients were visited in regular follow up intervals after treatment and at the final follow up the rotational movements of the forearm were measured. The findings were analyzed with Independent $\mathrm{T}$ and Chi-square tests. Findings: Ultimately 23 patients of the group 1 (intact ulnar styloid) and 24 of the group 2 (fractured ulnar styloid) completed the follow up period. At this time supination of the wrist and forearm in group 2 was significantly less than the group 1 ( $p<$ 0.001). Conclusion: It seems that the association of an extraarticular distal radius fracture with the fracture of ulnar styloid, at least in short term causes restriction of supination of the forearm, though the mechanism and clinical significance of this finding cannot be easily explained.
\end{abstract}

Keywords: Fracture, Distal radius, Ulnar Styloid, Forearm Rotation

\section{Introduction}

Distal radius fractures are among the most common bone fractures in adults, and comprise one sixth of referred fractures to the emergency rooms [1]. Extraarticular distal radius fracture with dorsal tilt of the distal fragment (Colles' fracture) is one of the common fracture patterns in this region for which many treatment modalities have been used, such as closed reduction and pin and plaster and percutaneous fixation of the fractured fragments [2]. This fracture is associated with many complications including extensor pollicis longus rupture, malunion, complex regional pain syndromes and especially limitation of rotational movements of the wrist and forearm [3]. Factors leading to decreased range of motion of the forearm have been studied [4] and many of these studies have examined distal radius fractures [5-10]. Although Frykman has noticed the importance of ulnar styloid fractures [11] and has based his classification upon the presence or absence of it, up to the best of our knowledge no study has examined the relation between ulnar styloid fractures and forearm rotation.

\section{Patients and Methods}

A prospective case control study was performed with participation of 70 patients with extraarticular distal radius fractures.

Inclusion criteria were as follows:

1) informed consent for participation in the study;

2) fe/male >18 years old;

3) Unilateral stable (absence of dorsal comminution, radial shortening less than $10 \mathrm{~mm}$ and angulation less than 25 degrees) extraarticular distal radius fracture;

4) Time between fracture and treatment less than 48 hours;

5) Absence of systemic disease affecting joints such as R.A; 
6) Absence of arthritic changes in distal radioulnar joint;

7) Absence of fracture and/or history of fracture in the same upper extremity;

8) In case of ulnar styloid fracture, absence of fracture extension to the base and less than $3 \mathrm{~mm}$ displacement;

9) Absence of piano key sign after reduction;

10) No displacement after initial closed reduction.

The patients were divided into two groups: "intact ulnar styloid" and "fractured ulnar styloid", respectively groups 1 and 2 (Frykman's types I and II).

All of the patients were treated by one surgeon and with closed reduction and casting. Long arm cast was applied in neutral rotation and after 3 weeks and changed to short arm cast after 3 weeks of weekly radiographic control. The short arm cast was removed after 3 additional weeks and the wrist and forearm rotation was encouraged. Physiotherapy was performed on all of the patients by an experienced physiotherapist for 10 sessions. At 3 months of the fracture, control radiograms were taken as a routine of the clinic. 18 weeks after cast removal the supination and pronation range of motion were measured. The patient was asked to hold a pen in each hand and rotate her/his wrists as much as possible, while the elbows were held in 90 degrees of flexion and on the flanks. The angle between the pen and the vertical axis was recorded as the supination and pronation range of motion. All of the measurements were made by a single physician unaware of the purpose of the study and of the patients' group. Before the measurements the patient was asked about probable complaints regarding "rotation" of the wrist and forearm. If the patient had any complaints, s/he was asked whether this had caused any problems with the job or daily activities. Finally the results were analyzed with computer Pentium 4 using SPSS 16 and Independent T-Test.

\section{Results}

47 patients were followed for at least 6 months after their fracture had occurred. The patients' demographics are shown in Table 1. The mean limitation of supination was $8.91 \pm 6.24$ for group 1 (intact styloid) and $25.4 \pm 13.29$ for group 2 (fractured styloid). Again the mean limitation of pronation was $4.7 \pm 3$ for group 1 (intact styloid) and $3.19 \pm 5.2$ for group 2 (fractured styloid). The difference between the two groups was statistically significant regarding the limitation of supination, but not about the limitation of pronation (Tables 2 and 3). At this time the most common and most significant complaint of the patients was about pain in their wrist while only 8 of them(all of the group 2) complained about limitation of their wrist rotation. None of them mentioned a significant functional problem regarding this limitation in rotation.
Table 1. Demographic characteristics of the patients.

\begin{tabular}{ccccc}
\hline & Group 1 & Group 2 & & P-Value \\
\hline age & $8.39 \pm 5.34$ & $56.41 \pm 0.85$ & T-Test & 0.689 \\
Female & 14 & 13 & Chi-Square & 0.642 \\
Male & 9 & 11 & & \\
$\begin{array}{c}\text { Dominant } \\
\text { side fractured }\end{array}$ & 10 & 13 & Chi-square & 0.567 \\
\hline
\end{tabular}

Radiograms revealed nonunion of the ulnar styloid in actually all of the patients in group 2. None of the patients in this group complained about ulnar sided wrist pain.

\section{Discussion}

The present study was conducted to assess the effect of presence of ulnar styloid fracture on the rotation of wrist and forearm in extraarticular distal radius fractures. Usually the limitation of supination and pronation in patients with distal radius fractures is attributed to fracture line extension to the distal radioulnar joint, in which case more serious treatments such as internal fixation and even open reduction has been advocated [8]. But in some cases limitation occurs even in the absence of fracture line extension to the joint, which may be attributable to triangular fibrocartilage complex (TFCC) injury. The limitation of supination in group 2 probably cannot be attributed to TFCC injury as generally a more than $3 \mathrm{~mm}$ displacement and/or fracture line extension to ulnar head are considered as signs of this injury. These were considered as exclusion criteria for prevention of bias in the present study. Frykman in his classic article mentioned the incidence of ulnar styloid nonunion in distal radius fractures as $60 \%$ [11]. Another study found ulnar styloid fracture in one third of distal radius fractures [13]. The same study noted the relation between distal radioulnar joint (DRUJ) dislocation and ulnar styloid fracture, as

Table 2. Rotation of the forearm at the last follow up.

\begin{tabular}{lcc}
\hline & Pronation & Supination \\
\hline Group 1, intact side & $89.82 \pm 1.07$ & $89.60 \pm 0.89$ \\
Group 1, fractured side & $85.12 \pm 2.71$ & $80.69 \pm 6.68$ \\
Group 2, intact side & $89.66 \pm 0.81$ & $89.66 \pm 0.96$ \\
Group2, broken side & $84.45 \pm 3.14$ & $64.22 \pm 12.91$ \\
\hline
\end{tabular}

Table 3. Comparison of the amount of decrease in range of motion in the two groups.

\begin{tabular}{lccl}
\hline & $\begin{array}{c}\text { Amount of } \\
\text { decrease in } \\
\text { group1 }\end{array}$ & $\begin{array}{c}\text { Amount of } \\
\text { decrease in } \\
\text { group 2 }\end{array}$ & P-Value \\
\hline Supination & $8.91 \pm 6.24$ & $25.24 \pm 13.29$ & $<0.001$ \\
Pronation & $4.70 \pm 3.00$ & $5.2 \pm 3.19$ & 0.523 \\
\hline
\end{tabular}


actually in every DRUJ dislocation the ulnar styloid was fractured, though the reverse was not true. In fact "severe displacement and extension of the fracture line to the ulnar head were evidence of joint instability. So DRUJ instability too, is not the reason for limitation of supination in our patients.

The finding that ulnar styloid nonunion was asymptomatic in all of our patients is in agreement with some other studies [14]. It has been noted that ulnar styloid fractures in association with distal radius fractures or not frequently lead to nonunion and most are asymptomatic [15], though this is controversial [1]. Whether the limitation of supination in our patients related to ulnar styloid nonunion or not is a subject that we can not

Perhaps the most convincing explanation for the findings of the present study would be the DRUJ capsule contracture, whiHh can lead to limitation of supination after distal radius fractures [5]. Ulnar styloid fracture indica0es injury, however trivial to the wrist ulnar side and reaction of the joints to trauma is familiar to orthopedic surgeons,

Our patients had no functional complaints of loss of their wrist rotation, despite that some of them had obviously noted the loss can be dLe to the fact that most of them were not manual labors and again the fact that the range of motion was in functional range. Morrey et al. found the functional range of motion for supoination and pronation to be 50 degrees for each [16]. Range of motion had not decreased to such extent in none of our patients.

The most important limitation of the present study is the shortness of follow up of our patients. Though it has been mentioned that after 3 months of cast removal the patient will recover to such extent that can return to sports [13], it would have been much better to have a longer follow up period for our patients.

\section{Conclusions}

Based upon the findings of the present study it seems that the association of ulnar styloid fracture with extraarticular distal radius fracture is accompanied by limitation of supination in wrist and forearm, though the mechanism can not be explained and the clinical significance is not clear. The most probable explanation for the present study findings would be DRUJ capsular contracture after wrist ulnar sided trauma.

\section{References}

[1] D. S. Ruch, "Fractures of the Distal Radius and Ulna," In: R. W. Bucholz, J. D. Heckman and C. Court-Brown, Eds., Rockwood and Green's Fractures in Adults, 6th Edition, Lippincot William's and Wilkins, 2006, pp. 909-965.
[2] A. H. Crenshaw Jr., "Fractures of Shoulder, Arm and Forearm,” In: S. T. Canale Ed., Campbell's Operative Orthopedics, 10th Edition, Mosby, Vol. 4, 2003, pp. 3785-3787.

[3] D. L. Fernandez and S. W. WolfeDistal, "Radius Fractures,” In: D. P. Green, R. N. Hotchkiss, W. C. Pederson and S. W. Wolfe, Eds., Green's Operative Hand Surgery, 5th Edition, Churchill Livingston, Vol. 1, 2005, pp. 645-710.

[4] C. E. Dumont, R. Thalmann, J. C. Macy, “The Effect of Rotational Malunion of the Radius and the Ulna on Supination and Pronation,” Journal of Bone and Joint Surgery, Vol. 84, No. 7, 2002, pp. 1070-1074. doi:10.1302/0301-620X.84B7.12593

[5] M. C. Tynan, S. Fornalski, P. J. McMahon, A. Utkan, S. A. Green, T. Q. Lee, “The Effects of Ulnar Axial Malalignment on Supination and Pronation,” Journal of Bone and Joint Surgery, Vol. 82-A, No. 12, 2000, pp. 17261731.

[6] A. J. Bronstein, T. E. Trumble and A. F. Tencer, "The Effects of Distal Radius Fracture Malalignment on Forearm Rotation: A Cadaveric Study," Journal of Hand Surgery. Vol. 22, No. 2, 1997, pp. 258-262. doi:10.1016/S0363-5023(97)80160-8

[7] W. B. Geissler, D. L. Fernandez and D. M. Lamey, "Distal Radioulnar Joint Injuries Associated with Fractures of the Distal Radius," Clinical Orthopaedics and Related Research, No. 327, 1996, pp. 135-146. doi:10.1097/00003086-199606000-00018

[8] J. Ishikawa, N. Iwasaki and A. Minami, "Influence of Distal Radioulnar Joint Subluxation on Restricted Forearm Rotation after Distal Radius Fracture," Journal of Hand Surgery, Vol. 30, No. 6, 2005, pp. 1178-1184. doi:10.1016/j.jhsa.2005.07.008

[9] K. J. Prommersberger, S. C. Froehner, R. R. Schmitt and U. B. Lanz, "Rotational Deformity in Malunited Fractures of the Distal Radius,” Journal of Hand Surgery, Vol. 29, No. 1, 2004, pp. 110-115. doi:10.1016/j.jhsa.2003.09.014

[10] T. Yasutomi, Y. Nakatsuchi, H. Koike and S. Uchiyama, "Mechanism of Limitation of Pronation/Supination of the Forearm in Geometric Models of Deformities of The Forearm Bones," Clinical Biomechanics, Vol. 17, No. 6, 2002, pp. 456-463. doi:10.1016/S0268-0033(02)00034-7

[11] G. Frykman, "Fracture of the Distal Radius Including Sequelae: Shoulder-Hand-Finger Syndrome, Disturbance in the Distal Radio-Ulnar Joint and Impairment of Nerve Function-A Clinical and Experimental Study,” Acta Orthopaedica, Vol. 108, Suppl., 1967, pp. 1-153.

[12] G. V. Oskarsson, P. Aaser and A. Hjall, "Do We Underestimate the Predictive Value of the Ulnar Styloid Affection in Colles Fractures?” Archives of Orthopaedic and Trauma Surgery, Vol. 116, No. 6-7, 1997, pp. 341-344. doi:10.1007/BF00433986

[13] M. M. May, J. N. Lawton and P. E. Blazar, "Ulnar Styloid Fractures Associated with Distal Radius Fractures: Incidence and Implications for Distal Radioulnar Joint Instability," Journal of Hand Surgery, Vol. 27, No. 6, 
2002, pp. 965-971. doi:10.1053/jhsu.2002.36525

[14] T. Tsukazaki and K. Iwasaki, "Ulnar Wrist Pain after Colles' Fracture. 109 Fractures Followed for 4 Years,” Acta Orthopaedica, Vol. 64, No. 4, 1993, pp. 462-464. doi:10.3109/17453679308993668

[15] B. D. Adams, "Distal Radioulnar Joint Injuries,” In: D. P. Green, R. N. Hotchkiss, W. C. Pederson and S. W. Wolfe
Eds., Green's Operative hand Surgery, 5th Edition, Churchill Livingston, Vol. 1, 2005, pp. 605-644.

[16] B. F. Morrey, L. J. Askew and E. Y. Chao, "A BiomeChanical Study of Normal Functional Elbow Motion," Journal of Bone and Joint Surgery, Vol. 63, No. 6, 1981, pp. 872-877. 